\title{
The Process Approach on the Basis of Digitalization as a Technology to Ensure the Efficiency of Enterprise's Management
}

\author{
Stankovska I. M.* \\ Department of Management and \\ Administration \\ Ivano-Frankivsk National Technical \\ University of Oil and Gas \\ Ivano-Frankivsk, Ukraine, \\ e-mail: irinastankovska@i.ua
}

\author{
Polyanska A.S. \\ Department of Management and \\ Administration \\ Ivano-Frankivsk National Technical \\ University of Oil and Gas \\ Ivano-Frankivsk, Ukraine, \\ e-mail:parvs@ukr.net \\ Savchuk S.V. \\ Department of Management and \\ Administration \\ Ivano-Frankivsk National Technical \\ University of Oil and Gas \\ Ivano-Frankivsk, Ukraine, \\ e-mail: svitlanansv555@ukr.net
}

\author{
Stankovskyi T.V. \\ Department of Management and \\ Administration \\ Ivano-Frankivsk National Technical \\ University of Oil and Gas \\ Ivano-Frankivsk, Ukraine, \\ e-mail: stankovskytaras@gmail.com
}

\begin{abstract}
The article substantiates the expediency of applying a process approach to ensure the effective management of the enterprise on the base of using digitalization. The key benefits of applying a process approach to enterprise management and actions that will ensure the effective implementation and quality of processes are identified. In order to ensure process efficiency, criteria, methods and stages of process optimization technology have been defined; modern methods of process formalization and process management systems are analyzed. A mathematical model of selecting the most effective alternative to process improvement was applied and the results of calculations were obtained by using a program product implemented in Python.
\end{abstract}

Keywords - process approach, optimization, digitalization, efficiency, quality, mathematical model, competitiveness, Python

\section{INTRODUCTION}

Dynamic changes in the markets supply and demand trends of products and services, fierce competition, increasing requirements for quality and safety of production are factors that require enterprises to use modern management technologies. A modern enterprise is a complex emergent system that is constantly influenced by the environment in which it operates. The process management approach identifies the basic processes required to produce competitive products in complex management environments, along with defining their interaction and managing them. The advantage of the process approach is that it provides continuous control over the interconnections of individual processes within the process system, as well as their connection and interaction. To ensure effective interaction between processes, it is necessary to take into account a large amount of information, work with large amounts of data, consideration of all variables of environmental impact, which requires the use of a process approach in enterprise management on the basis of digitization. The process approach gives an opportunity to distinguish separate stages in the processes of production, maintenance, management.

The process approach makes it possible to take advantage of the digitalization potential of management processes and to ensure their efficiency by quickly calculating the results of each alternative solution of the set task.

Problems of the study of process management at the enterprise are addressed by foreign and Ukrainian scientists, in particular: J. Harrington, K. Esseling, H. Van Nimwegen [1], V. Repin, V. Eliferov [2], L. Shemaeva, K. Bezgin [3], G. Nikitenko [4] and others.

Nowadays, the problem of digitalization and digital transformation is widely considered in the context of the implementation of the Industry 4.0 policy as a new stage of industrial revolution development [5], as well as in the international and national program documents defining the perspectives and priorities of modern economic development [6-12].

But the problem under study needs further attention, as advanced countries that are actively engaged in digital transformation not only provide the digitization and digitalization of processes, but also the change of processes, their interrelation, communications and other connected activities. New management concepts are being developed, and accordingly to these the technologies are changing that will ensure the efficiency of process management at the enterprise.

\section{THE PURPOSE OF THE RESEARCH}

Investigation of the relevance and importance of the process approach for structuring enterprise processes in order to enable them to be optimized on the basis of efficiency criteria digitalization. 


\section{THE RESEARCH METHODOLOGY}

To study the process approach on the basis of digitalization, we apply a mathematical model of justification of trade process efficiency and a program implemented in Python environment for two-criteria optimization of the process of competitiveness management. To determine the processes of effective management of enterprise competitiveness, we use the "quality loop". According to the standards (ISO 9000), for the effective operation of the company, each of the processes that form the loop and ensure their quality must be implemented. However, there is a need for economic justification for the implementation of each process, which requires certain financial costs that the company should take into account when deciding on the optimization of the management process. To solve this problem, we used a software product for calculating the cost-effectiveness of alternative options for improving processes based on the implementation of the "quality loop" on the criteria of average yield - risk [13-16].

During calculation the resulting indicators were used:

$N P V(L)$ - net present value of losses in the absence of process improvement;

$N P V(C)$ - net present value of total investment costs to improve the process;

$M(N P V(\tilde{W}))$ - the mathematical expectation of a random losses;

$\sigma(N P V(\tilde{W}))-$ the standard deviation of the NPV of the random losses;

$\operatorname{VaR}_{k \sigma}$ - three Sigma risk indicator.

The following formulas were used to find these quantities:

$\mathbf{C}=\left(C_{0}, C_{1}, \ldots, C_{T}\right)-$ total flow of capital and maintenance costs;

$\tilde{W}=\left(0, \tilde{W}_{1}, \ldots \tilde{W}_{T}\right)-$ flow of accidental losses;

$\mathbf{L}=\left(0, L_{1}, \ldots, L_{T}\right)-$ flow of possible projected losses;

$$
\tilde{F}=L-C-\tilde{W}-\text { Contingent cash flow }
$$

A generalized characteristic of investment effectiveness in improving management processes in the surveyed enterprises is the Net Present Value (NPV)

$$
\operatorname{NPV}(\tilde{F})=\sum_{t=0}^{T} \frac{\tilde{F}}{(1+r)^{t}}
$$

where $r$-effective interest rate.

The mathematical expectation and variance of the magnitude of investment efficiency is calculated by the formulas:

$$
M(N P V(\tilde{F}))=\sum_{t=0}^{T} \frac{M(\tilde{F})}{(1+r)^{t}}
$$

$$
D(N P V(\tilde{F}))=\sum_{t=0}^{T} \frac{D\left(\tilde{F}_{t}\right)}{(1+r)^{2 t}}
$$

The relative value of NPV of conditionally saved funds has been introduced in investing in process improvement:

$$
\tilde{f}=N P V(\tilde{F}) / N P V(L),
$$

where:

$$
N P V(\mathbf{L})=\sum_{t=0}^{T} \frac{L_{t}}{(1+r)^{t}}
$$

Based on the formulas given above, we have determined the mathematical expectation and standard deviation of this value, which are denoted respectively $M(\tilde{f})$ and $\sigma(\tilde{f})$ :

$$
\begin{aligned}
& M(\tilde{f})=M(N P V(\tilde{F})) / N P V(L), \\
& \sigma(\tilde{f})=\frac{(D(N P V(\tilde{F})))^{1 / 2}}{N P V(L)} .
\end{aligned}
$$

Output data: project duration $-\mathrm{T}=5$, interest rate $\mathrm{r}=$ $0.14, \mathrm{k}-$ risk factor over a specified period $\mathrm{k}=3$. The calculations were implemented in Python.

With help of packet Numpy there was generated Object and calculated $r_{i j}=\prod_{m=1}^{M} s_{m i j}$ probability of losing one of the process improvement alternatives.

\section{STATEMENT OF THE BASIC MATERIAL}

The expediency of applying the process approach in management is laid down in the international standards ISO 9000: 2015, ІDТ: SSТС (ДСТУ) ISO 9000: 2015, which are harmonized with international normative documents. It states that "The organization has processes that could be identified, measured and improved. These processes interact to deliver results that are consistent with the goals of the organization and cross its functional boundaries. Some processes may be critically important, while others may not. Processes are interconnected work with inputs to convert them to outputs" [17]. Therefore, it is important for each enterprise to identify all the process, necessary for effective work. In addition, the application of the process approach should be considered as a continuous interaction of related management functions, each of which is a separate process consisting of the implementation of specific sequential or parallel unit operations. To manage processes effectively at the enterprise, it is necessary to differentiate properly and improve the following elements of the process approach:

- Core processes that are end-user oriented and generate revenue;

- Processes that provide basic processes with resources;

- The processes that implement management functions.

There are also separate processes of development (innovation) [3]. 
Therefore, the process approach in management requires the identification of processes, their owners, a documented description of processes, the definition of indicators of evaluation and monitoring of processes.

The performance and interconnectivity of processes at the enterprise is defined by ISO 9000: 2015, which states that "Consistent and predictable results are achieved more efficiently and effectively if activities are understood and managed as interrelated processes that function as a coherent system. Understanding how this system delivers results enables the organization to optimize the system and its performance".

The application of the process approach gives the key benefits that are provided in the standards of ISO 9000: 2015 [1] namely:

- Increasing the ability to focus efforts on key processes and opportunities to improve them;

- Achieving consistent and predictable results in a system of agreed processes;

- Optimizing efficiency through efficient process management, efficient use of resources and reduction of cross-functional barriers;

- Ensuring that the organization builds stakeholder confidence in its consistency, effectiveness and efficiency.

To effectively implement and ensure the quality of processes in accordance with the standards of SSTC (ДСТУ) ISO 9000: 2015, the following actions are required:

- To identify the goals of the enterprise and the processes required to achieve them;

- To establish process management powers, responsibilities, and obligations;

- To analyze the capabilities of the enterprise and identify resource constraints;

- To determine the interdependence between the processes and the enterprise management system, to analyze the impact of changes in individual processes on the activity of the enterprise as a whole;

- To ensure that processes and their relationships are managed as a single system, in order to achieve goals efficiently;

- To ensure the availability of information necessary for the functioning and improvement of processes;

- To monitor, analyze and evaluate the efficiency and effectiveness of processes;

- To provide risk management that can affect the outputs of processes and the overall performance of the enterprise;

- To ensure standardization in approaches to process structuring and management;

- To ensure the link between technology and staff;
- To define regulations, job descriptions, organization of training of personnel, decision of tasks on automation of management processes.

The main criteria for process management should be their customer orientation and effectiveness of their implementation by optimizing the use of resources.

The process of using financial resources should have: clear definition and direction of use of resources; limits of use are established; control of target use and compliance with established limits.

The process of using human resources requires: a clear definition of functional responsibilities; use of personnel in accordance with functional responsibilities; identifying features that require outsourcing and more.

The process of using material resources includes: rationing, order of exploitation, repairs, prevention and more.

Information resources related to consumer research and satisfaction related to the processes of collecting and processing large volumes of information

Therefore, it is important for small and medium-sized enterprises in Ukraine to use inexpensive universal information processing systems and methods, and to be able to quickly and reasonably choose the best options for implementing the relevant processes.

The following methods are used to optimize process management: analytical; digitization; formal-universal; based on experience; Benchmarking; teamwork technologies.

Each of these methods has some limitations in application (Table 1)

TABLE I. FEATURES AND LIMITATIONS OF USING METHODS

\begin{tabular}{|l|l|l|}
\hline Method & Specifics & Limitations \\
\hline analytical & $\begin{array}{l}\text { formalization of } \\
\text { processes }\end{array}$ & $\begin{array}{l}\text { availability of software } \\
\text { and qualified staff }\end{array}$ \\
\hline digitization & $\begin{array}{l}\text { Knowledge of } \\
\text { digitization } \\
\text { methodology, large } \\
\text { amounts of } \\
\text { information }\end{array}$ & $\begin{array}{l}\text { availability of technical } \\
\text { capabilities }\end{array}$ \\
\hline $\begin{array}{l}\text { formally } \\
\text { universal }\end{array}$ & $\begin{array}{l}\text { system structuring, } \\
\text { logical approach, } \\
\text { experiment } \\
\text { modeling }\end{array}$ & $\begin{array}{l}\text { lack of qualified } \\
\text { specialists, software }\end{array}$ \\
\hline $\begin{array}{l}\text { based on } \\
\text { experience } \\
\text { experience, knowing } \\
\text { someone else's } \\
\text { experience }\end{array}$ & $\begin{array}{l}\text { effective process } \\
\text { structuring, speed of } \\
\text { realization of knowledge } \\
\text { and skills }\end{array}$ \\
\hline benchmarking & $\begin{array}{l}\text { access to best } \\
\text { practices }\end{array}$ & $\begin{array}{l}\text { possibilities to introduce } \\
\text { new approaches: } \\
\text { financial, competent, } \\
\text { technological }\end{array}$ \\
\hline $\begin{array}{l}\text { teamwork } \\
\text { technologies }\end{array}$ & $\begin{array}{l}\text { qualified } \\
\text { management at the } \\
\text { enterprise }\end{array}$ & $\begin{array}{l}\text { availability of qualified } \\
\text { management staff and } \\
\text { technical resources }\end{array}$ \\
\hline
\end{tabular}

To implement the process approach, it is advisable to use modern methods of the process description formalization.

- Workflow Management - Workflow management that uses a graphical representation of the flow of tasks in the process associated with the sub 
processes, including specific jobs, information dependencies and the sequence of decisions and work. To depict the flow of work, use a block diagram, a dragon diagram, or a graph consisting of operations (works), logic symbols, and arrows.

- BPM business process management - answers the question of where, when, why, how and what work is performed and who is responsible for its execution

- BPMN Business Process Model and Notation - a system of notation for process modeling.

- EPC diagram, event-driven process chain - process flowchart used for business modeling and others.

Also, enterprises use ready-made systems for managing certain types of processes, namely:

- $E R P$ - production resource management systems,

- WMS - Warehouse Process Automation Systems,

- $T M S$ - automation systems for transport and traffic management,

- $C R M$ - systems for collecting and analyzing information on the market and supply and others.

Each of these management concepts focuses on speed, quality, numerical management and organizational flexibility. However, it should be noted that the implementation of such systems is time-consuming and costly for the enterprise.

The feasibility of using each of the methods depends on the specific activity of the enterprise and the structure of the management process. As noted above, it is advisable to consider the process approach to enterprise management as a system of interrelated processes. Each process needs to be constantly monitored and optimized. Optimization of all processes at the enterprise should be carried out taking into account the peculiarities and interrelationships of all involved in the implementation of the tasks set processes. Identifying, monitoring and evaluating the execution of processes and their efficiency and optimization capabilities require formalization and mathematical representation. Digitization significantly improves the process of working out large amounts of information to perform the necessary mathematical calculations $[18,19]$.

Appropriate optimization technology should be applied to determine the optimal process, taking into account the following steps.

- Selection of optimization criteria.

- Ranking of key processes at the enterprise by a certain criterion.

- Characterization of the set goals for optimization and determination of its criteria.

- The clarity of the description of the business process to determine the type of optimization.

- Taking into account ambiguity of optimization by different criteria.
- Availability of information on process optimization [2, p. 119, 20].

Practical implementation of the mathematical model presented above to select the most effective variant of the process of ensuring competitiveness by the criteria average yield - risk, conducted on the basis of the software created in Python environment. For the optimization selected and formalized individual processes (Table 2), which influence the competitiveness of the wholesale trade enterprises. In our view, the processes in Table 2 are most closely related to the process management criteria we choose: customer orientation and resource optimization. Profitability indicates how much the company is focused on the consumer, risk how much optimally used resources.

Wholesale is selected for the study that directly interacts with both consumers and manufacturers of finished products and are most likely to respond to changing supply and demand in the market.

TABLE II. FORMALIZATION OF COMPETITIVENESS ASSURANCE PROCESSES

\begin{tabular}{|l|l|}
\hline Process number & \multicolumn{1}{c|}{ The content of the process } \\
\hline 1 & Marketing \\
\hline 2 & Development and design of services \\
\hline 3 & Purchase of goods \\
\hline 4 & Process planning and development \\
\hline 5 & Provision of services \\
\hline 6 & Control, analysis \\
\hline 7 & Packing and storage \\
\hline 8 & Sales and service \\
\hline 9 & Delivery \\
\hline 10 & Technical assistance and service \\
\hline 11 & Utilization \\
\hline \multicolumn{2}{|l|}{ Source: formed on the base of quality loop elements } \\
\hline
\end{tabular}

Eight alternatives to process improvement (API) have been considered, listed below. Each process includes an appropriate set of operations to ensure its implementation:

API 1 - 1, 5, 6, 7, 8, 9, 10, 11;

API $2-1,4,6,7,8,9,10$;

API 3 - 2, 5, 6, 7, 8, 9, 10;

API $4-3,5,7$;

API 5 - 1, 4, 6, 7, 8, 9;

API 6 - 3, 4, 6, 7, 9, 10, 11;

API 7 - 3, 4, 6, 7, 8, 9, 11;

API $8-1,4,6,7,8,9,10$.

The results of the calculations in the criterion space are shown in Fig. 1.

It can be seen from Fig. 1 that only variants of API 1 and API 6 are unsubstantiated. They form many Pareto-optimal solutions. It should be noted that the best profile of the process according to the criterion of "three sigma" is API 6.

Therefore, the best alternative to the criteria of profitability-risk is to improve the process of API 6. The proposed model is versatile and can be used to select the most effective option for implementing any process by the criterion of efficiency. 
So, the further development of process management modeling has been achieved on the base of a mathematical model application with using of digitized data on the activities of wholesale companies.

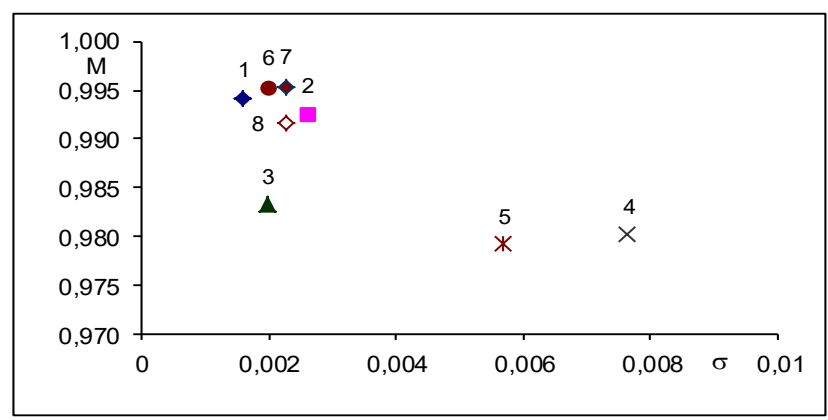

Fig. 1. Alternative options for improving the competitiveness process in the space of medium-risk-yield criteria.

This has allowed optimizing the choice of alternatives for process improvement according to the criterion of economic efficiency "profitability-risk".

\section{CONCLUSION}

As a result of the conducted research the obtained results allow to summarize:

- The expediency of using the process approach in enterprise management based on the standards of ISO 9000: 2015 was established in order to improve the efficiency of the enterprise as a whole;

- Identified the key benefits of applying a process approach on the base of digitalization in enterprise management;

- Identified the actions necessary for the effective implementation and quality assurance of processes;

- Criteria and methods of process optimization are selected;

- The stages of technology of process optimization, in particular on the basis of digitalization, are indicated;

- Modern methods of process formalization and process management system are analyzed;

- Mathematical model of choice of the most effective alternative variant of process improvement is applied

- The results of the calculations were obtained with the help of a program implemented in python environment.

\section{REFERENCES}

[1] K. Harrington, H. Esseling, Van Nimwegen, Business Process Optimization: Documentation, Analysis, Management, Optimization. Alphabet; St. Petersburg: BMro, 2009.
[2] V. Repin, V. Elifer, Process approach to management. Business Process Modeling . 3rd ed., M.: RIA “Standards and Quality”, 2005.

[3] L. Shemaeva, K. Bezgin, Quality management of business processes at the enterprise. Kharkiv National Economic University, Kharkov: View. KNEU, 2011. [in Ukraine]

[4] G. Nikitenko, Zh. Prorochuk, Basic theoretical aspects of reengineering of business processes of trading enterprises. Publishing house: Education and Science s.r.o., 2009, [Online]. Available:http://www.rusnauka.com/16_NPRT 2009/ Economics 147747 .doc.htm.

[5] L. Sogida, Industry 4.0 and its impact on the countries of the world, Mukachiv State University, pp. 58-64. [Online]. Available: http://economyandsociety.in.ua/journal/17_eng/9.pdf

[6] H. Kagermann, R. Anderl, J. Gausemeier, G. Schuh, W. Wahlster, Industrie 4.0 in Global Context Strategies for Cooperating with International Partners. Herbert Utz Verlag GmbH, 2016.

[7] R. Geissbauer, S. Schrauf, V. Koch, S. Kuge, Industry 4.0 Opportunities and Challenges of the Industrial Internet. Pricewaterhouse Coopers Aktiengesellschaft Wirtschaftsprüfungsgesellschaft, December, 2014.

[8] Industry 4.0, Challenges and solutions for digital transformation and the use of exponential technologies Audit. Tax. Consulting. Corporate Finance. Deloitte. 2014

[9] M. Rüßmann, M. Lorenz, P. Gerbert, M. Waldner, Industry 4.0. The Future of Productivity and Growth in Manufacturing Industries. Boston Consulting Group, April 2015.

[10] Readiness for the Future of Production Report 2018:Insight Report, World Economic Forum, 2018, [Online]. Available: http://www3.weforum.org/docs/FOP_Readiness_Report_2018.pdf.

[11] Only 25 countries are well positioned to benefit from Industry 4.0 according to a new World Economic Forum report, 13 February, [Online]. Available: 2018,https://www.edb.gov.sg/en/news-andresources/insights/innovation/only-25-countries-wellpositioned-tobenefit-from-industry-4-0- a.html.

[12] Digital Transformation Monitor Key lessons from the national, European Commission 4.0 policy initiatives, May, 2017.

[13] V. Dudikevych, V. Ivanyuk, and I. Prokopyshin, "Effectiveness of Investments in Systems for the Protection of Premises Against the Leakage of Language Information“, Computer Printing Technologies, 2014, 32, pp. 20-28. [in Ukraine]

[14] F. Egorov, E. Tiskina, V. Khoroshko, "Problems of Information Protection", Information Protection, 2009, 1, pp. 5-12.

[15] S. Zapechnikov, A. Polyakova, "Investigation of models for estimating the optimal volume of investments in information security", Bulletin of the Russian State Humanities Universit, 2012, 14 (94), pp. 153-168. [in Russian]

[16] I. Prokopyshyn, "Two-criteria analysis of the effectiveness of conservative systems of information protection", in Proc. 5th International Scientific and Technical Conf. Information Protection and Security of Information Systems, Lviv, 02-03 June 2016], NU "Lviv Polytechnic", pp. 34-35, 2016. [in Ukraine]

[17] Quality management systems. Basic Terms and Glossary (ISO 9000: 2015, IDT): SSTC ISO 9000: 2015,. K .: State Consumer Standard of Ukraine, 2016. [in Ukraine]

[18] F. Imgrund1, M. Fischer1, Ch.n Janiesch1, A. Winkelmann, Approaching Digitalization with Business Process Management pp. 1725-1736, [Online]. Available: http://mkwi2018.leuphana.de/wpcontent/uploads/ MKWI_193.pdf

[19] Digitization, digitalization and digital transformation: the differences. [Online]. Available: https://www.i-scoop.eu/digitizationdigitalization-digital-transformation-disruption/

[20] S. Kovaliov, Optimization of Business Processes, [Online]. Available: http://www.betec.ru/index.php?id=06\&sid=55. 